\title{
Simple isophthalamides/dipicolineamides as active transmembrane anion transporters
}

Giacomo Picci, ${ }^{a}$ Israel Carreira-Barral, ${ }^{b}$ Daniel Alonso-Carrillo, ${ }^{b}$ David Sanz-González, ${ }^{b}$ Pablo Fernández-López, ${ }^{b}$ María García-Valverde, ${ }^{b}$ Claudia Caltagirone $^{a, *}$ and Roberto Quesada ${ }^{b, *}$

${ }^{a}$ Dipartimento di Scienze Chimiche e Geologiche, Università degli Studi di Cagliari, s.s. 554 Bivio Sestu, I-09042 Monserrato, CA, Italy

E-mail: ccaltagirone@unica.it

${ }^{b}$ Departamento de Química, Universidad de Burgos, Burgos 09001, Spain

E-mail: rquesada@ubu.es 
Simple isophthalamides/dipicolineamides as active transmembrane anion transporters

Eight $N, N^{\prime}$-diarylisophthalamide/dipicolineamide derivatives have been synthesized and fully characterized, both in solution and in the solid state. The transmembrane anion transport properties of these compounds have been studied by chloride-selective electrode and fluorescence experiments. The substitution pattern of the aromatic moieties determines the transport properties of these systems, with those containing electron-withdrawing groups in their structures being the most active ones of the series.

Keywords: anion binding, anion transport, ion-selective electrode, liposomes

\section{Introduction}

The last few years have witnessed important advances in the development of small molecules capable of facilitating the transmembrane transport of anions. ${ }^{1-3}$ These anion selective ionophores, anionophores, mimic the function of transmembrane ion transport proteins. These proteins play key roles in processes such as ion homeostasis, membrane polarization or $\mathrm{pH}$ level control. ${ }^{4}$ Thus, anionophores could display biological activities, and have been explored as anticancer drug candidates, ${ }^{5-7}$ antimicrobial agents, ${ }^{8,9}$ or protein molecular prosthetics. ${ }^{10,11}$

The vast majority of reported anionophores use hydrogen-bonding interactions to coordinate the anion, thus forming a lipophilic supramolecular complex capable of diffusing across the lipid bilayer. ${ }^{12,13}$ Release of the anion in the other leaflet of the membrane completes the transport process. Isophthalamides and dipicolineamides constitute classic examples of anion binding motifs. After the seminal report by Crabtree and colleagues, ${ }^{14}$ these motifs and related variations were extensively employed in the design of anion receptors. Examples of isophthalamide and isophthalamide-like molecules have also been studied as transmembrane carriers. ${ }^{15,16}$ 
Although simple isophthalamides have been proven ineffective as transmembrane anion carriers, ${ }^{17}$ decoration of this motif with hydroxyl groups in the 4 and 6 positions of the aromatic group resulted in the stabilization of the appropriate conformation of the anion binding motif and polarization of the $\mathrm{N}-\mathrm{H}$ groups, activating transmembrane anion transport. ${ }^{18}$ Likewise, preorganization of the binding cleft in dipicolineamides also proved useful in terms of transmembrane chloride transport. ${ }^{19}$ Polarization of the hydrogen-bonding donor groups to enhance the anion binding is frequently used to increase the anion transport properties of anionophores. In this regard, introducing fluorinated substituents is particularly effective since, in addition to the electronwithdrawing effect of these substituents, an increase of the lipophilicity of the molecule is obtained. ${ }^{20}$ Indeeed, lipophilicity is a key parameter to tune the transmembrane activity of these compounds. ${ }^{21,22}$

In this work we have synthesized and studied several $N, N^{\prime}$-diarylisophthalamide derivatives and one $N, N^{\prime}$-diaryldipicolineamide to assess the influence of their substitution pattern in the binding and transport properties of these compounds.

\section{Results and discussion}

Compounds L1-L8 (Figure 1) were prepared by condensation of isophthaloyl chloride or 2,6-pyridinedicarbonyl dichloride with the appropriate amine. A variety of substituents in the aromatic rings was assayed, including electron-donating alkyl groups (L1, L2) and electron-withdrawing halides, trifluoromethyl, and pentafluorosulfanyl substituents (L3-L8). 


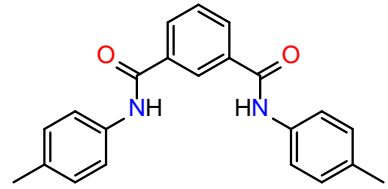

L1<smiles>O=C(Nc1cc(C(F)(F)F)cc(C(F)(F)F)c1)c1cccc(C(=O)Nc2cc(C(F)(F)F)cc(C(F)(F)F)c2)c1</smiles>

L4

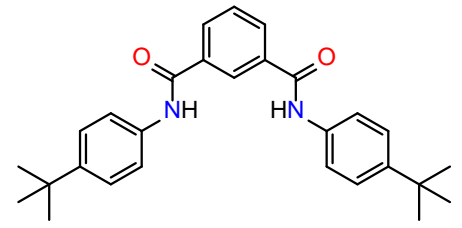

L2<smiles>O=C(Nc1ccc(C(F)(F)F)cc1)c1cccc(C(=O)Nc2ccc(C(F)(F)F)cc2)c1</smiles>

L5<smiles>O=C(Nc1ccc(Cl)cc1)c1cccc(C(=O)Nc2ccc(Cl)cc2)c1</smiles>

L3<smiles>O=C(Nc1ccc(F)cc1)c1cccc(C(=O)Nc2ccc(F)cc2)c1</smiles>

L6

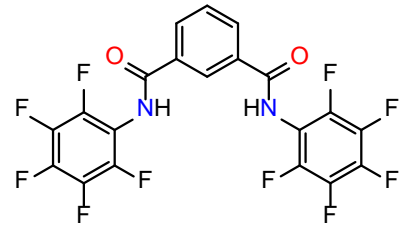

L7

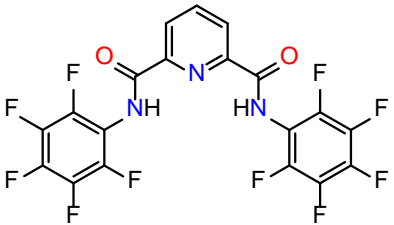

L8

Figure 1. Structures of compounds L1-L8 included in this study.

All compounds were fully characterized spectroscopically in solution, and bis(4chlorophenyl)isophthalamide L3 was also characterized in the solid state (Figure 2). Slow evaporation of a solution of compound $\mathbf{L} 3$ in $n$-butanol provided colorless single crystals, suitable for X-ray diffraction studies. The molecule presents an anti-anti conformation, with the two carbonyl groups pointing in the same direction as the $\mathrm{C}-\mathrm{H}$ fragment of the central aromatic ring. The aromatic rings are not coplanar and display a three-step-staircase structure, with the central ring and the carbon atoms of the carbonyl groups in the middle, and each of the 4-chlorophenyl- substituents and $\mathrm{N}-\mathrm{H}$ fragments in the first and third steps. This lack of coplanarity is due to crystal packing, as this spatial arrangement allows the maximization of intermolecular interactions. Thus, each isophthalamide molecule interacts with four neighboring molecules by hydrogenbonding interactions (Figure 2): with two of them through its $\mathrm{N}-\mathrm{H}$ fragments and with 
the other two molecules through its carbonyl groups.
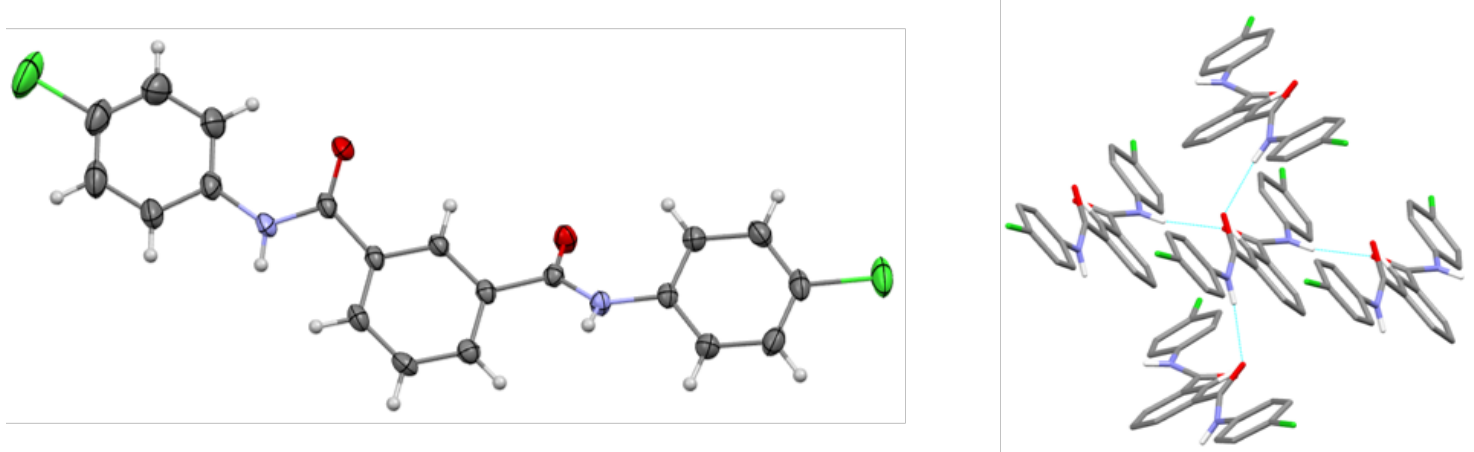

Figure 2. Left: X-ray molecular structure of compound L3. Hydrogen atoms, except those involved in hydrogen-bonding interactions, have been omitted for the sake of simplicity. The ORTEP plot is at the $30 \%$ probability level. Right: intermolecular interactions in the crystal (blue dotted lines).

The ability of these compounds to interact with chloride was assayed by ${ }^{1} \mathrm{H}$ NMR titration experiments in DMSO- $d_{6}$. The association constants were calculated using the WinEQNMR software ${ }^{23}$ and are shown in Table 1 . In all cases the titration profiles (see ESI) were fitted to 1:1 (L:Cl-) binding isotherms following the downfield shift of the signal due to the protons of the amide groups. A representative stack plot of ${ }^{1} \mathrm{H}$ NMR spectra corresponding to a titration experiment of $\mathbf{L 5}$ with TBACl is shown in Figure 3. Although the calculated $K_{\mathrm{a}}$ values under these conditions are small, an interesting trend is observed. Transporters with electron-withdrawing groups (L3-L8) bind more strongly than L1-L2, lacking these groups. Furthermore, the calculated $K_{\mathrm{a}}$ value for $\mathbf{L 7}$ is the smaller among this group of transporters (L3-L8), possibly due to the repulsion between the bound anion and the fluorine atoms. The higher calculated $K_{\mathrm{a}}$ value among this series corresponds to L8, probably reflecting the preorganization of the binding pocket in the dipicolineamide. The ${ }^{1} \mathrm{H}$ NMR spectra also indicate that the aromatic C-H group placed among the amide groups (in L1-L7) interacts with the 
anion, as evidenced by the deshielding of this proton's signal. This observation suggests a syn-syn conformation of the receptors in solution upon chloride coordination.

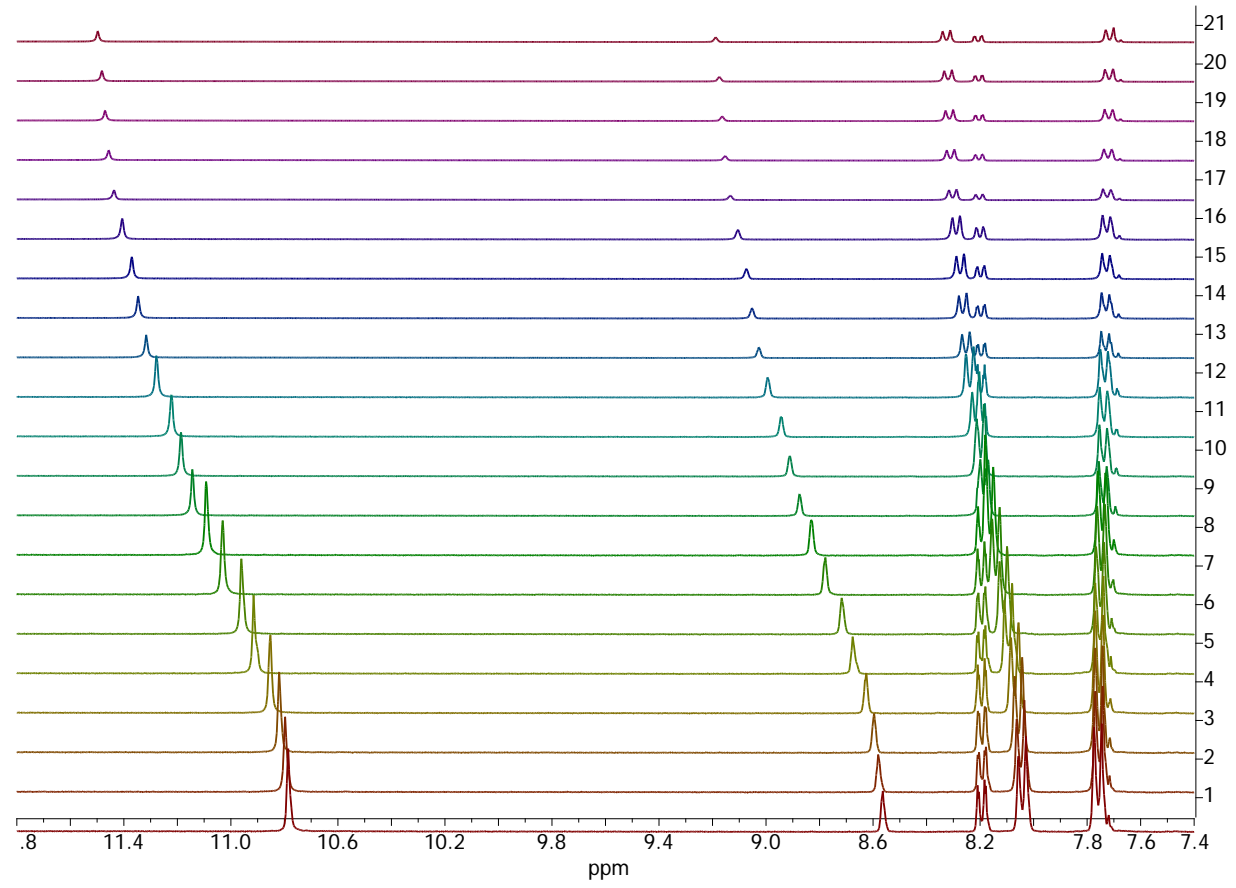

Figure 3. Excerpt of the ${ }^{1} \mathrm{H}$ NMR spectra (300 MHz, DMSO- $d_{6}$ ) obtained upon addition of different aliquots of TBACl to a solution of $\mathbf{L 5}$.

The transport properties of the compounds were first evaluated in model phospholipid vesicles using a chloride-selective electrode. ${ }^{24}$ In these assays chloridecontaining liposomes composed of 2-oleoyl-1-palmitoyl-sn-glycero-3-phosphocholine (POPC) are suspended in an isotonic solution and the studied compounds are added as an aliquot of DMSO solution (see ESI for details). The experiments are repeated at least in triplicate using different batches of vesicles and the results obtained using different concentrations of the compound are analyzed employing the Hill equation. As input, the chloride efflux observed after $300 \mathrm{~s}$ of the experiment is used. The concentration of compound needed to release $50 \%$ of the encapsulated chloride corresponds to $\mathrm{EC}_{50}$. The lower the value of this parameter, the more potent the compound is (Table 1). Chloride/nitrate and chloride/bicarbonate exchanges were studied, the $\mathrm{EC}_{50}$ values for 
the latter being, in most of the cases, between one and two orders of magnitude higher than those obtained for the former. This is the commonly observed trend and it is in line with the Gibbs free energy of hydration of both anions $\left(\Delta G_{h y d}=-335\right.$ and $-300 \mathrm{~kJ} \cdot \mathrm{mol}^{-1}$ for bicarbonate and nitrate, respectively ${ }^{25}$; nitrate is more lipophilic than bicarbonate and, consequently, easier to extract into the membrane.

The first observation is that isophthalamides bearing tolyl- or (tert-butyl)phenylsubstituents, $\mathbf{L} \mathbf{1}$ and $\mathbf{L 2}$, are not active as anion carriers. This result is in agreement with previous studies. ${ }^{15,17}$ On the other hand, electron-withdrawing substituents proved successful to improve the transport activity. Compound L3 was found moderately active in this assay whereas displaying low activity in the chloride/bicarbonate exchange assay (releasing 35\% of encapsulated chloride at 8\% carrier:phospholipid molar ratio).

Table 1. Association constants $K_{\mathrm{a}}\left(\mathrm{M}^{-1}\right)$ with chloride (added as its tetrabutylammonium salt) determined from ${ }^{1} \mathrm{H}$ NMR titration experiments in DMSO- $d_{6}$ at $293 \mathrm{~K}$, transport activities expressed as $\mathrm{EC}_{50}(\mu \mathrm{M})$ and $\log \mathrm{P}$ values ${ }^{28}$ for compounds

\section{L1-L8.}

\begin{tabular}{lllll}
\hline Compound & $\boldsymbol{K}_{\mathbf{a}}\left(\mathbf{C l}^{-}\right)$ & $\begin{array}{l}\mathbf{E C}_{\mathbf{5 0}} \\
\mathbf{N O}^{-}{ }^{-} \mathbf{\mathbf { C l } ^ { - }}\end{array}$ & $\begin{array}{l}\mathbf{E C _ { 5 0 }} \\
\mathbf{\mathbf { H C O }}{ }^{-} / \mathbf{C l}^{-}\end{array}$ & $\mathbf{l o g P}$ \\
\hline $\mathbf{L 1}$ & $10.2 \pm 0.2$ & $-*^{1}$ & $-*^{1}$ & 3.88 \\
\hline $\mathbf{L 2}$ & $14.5 \pm 0.3$ & $-*^{1}$ & $-*^{1}$ & 5.70 \\
\hline $\mathbf{L 3}$ & $26.0 \pm 0.6$ & 0.79 & $-*^{2}$ & 4.77 \\
\hline $\mathbf{L 4}$ & $36.2 \pm 2.3$ & 0.15 & 12.24 & 5.56 \\
\hline $\mathbf{L 5}$ & $30.3 \pm 1.4$ & 0.32 & 5.01 & 4.73 \\
\hline $\mathbf{L 6}$ & $28.0 \pm 0.6$ & 0.22 & 15.57 & 4.71 \\
\hline $\mathbf{L 7}$ & $22.0 \pm 0.4$ & 3.05 & 10.3 & 4.35 \\
\hline $\mathbf{L 8}$ & $47.0 \pm 0.5$ & 2.20 & 6.03 & 4.21 \\
\hline
\end{tabular}

$*^{1}$ : No significant chloride efflux was detected with compound added up to $5 \%$.

$*^{2}: \mathrm{EC}_{50}>>8 \%$ (at $8 \%$ just $35 \%$ of encapsulated chloride is released). 
The trifluoromethyl- and pentafluorosulfanyl-substituted derivatives (L4-L6) were found the most active derivatives, with $\mathrm{EC}_{50}$ values in the submicromolar range in the chloride/nitrate exchange assay. Perfluorosubstituted compounds L7 and L8 were found less active than L4-L6. Moreover, the relative activity in the chloride/nitrate and chloride/bicarbonate exchange assays was found more similar than for the other derivatives (the ratio of the $\mathrm{EC}_{50}$ values in these assays was 2-2.5 times compared to differences in excess of an order of magnitude typically found for other compounds). A possible explanation for these observations is the low solubility of $\mathbf{L 7}$ and $\mathbf{L 8}$, which could affect the outcome of the experiments. Additionally, interplay with other weak forces such as anion- $\pi$ interactions in the transmembrane transport event can not be ruled out for these compounds. ${ }^{26,27}$

In order to support the chloride-selective electrode transport studies, emission spectroscopy experiments were conducted. To confirm the lack of detergent effect exerted by these compounds, the well-established carboxyfluorescein-based assay was performed. In these experiments, chloride- and carboxyfluorescein-loaded liposomes are suspended in an isotonic sodium sulfate aqueous solution. After one minute the corresponding carrier is added to the suspension and the emission changes monitored for five minutes. At the end of the experiment, a detergent is added to lyse the vesicles and release the entrapped carboxyfluorescein (see ESI for more details). Carboxyfluorescein is encapsulated at self-quenching concentrations and its release is signaled by an increase of the fluorescence as a result of the dilution of the dye. The results showed almost no fluorescence changes upon addition of compounds until the surfactant is added, thus ruling out the formation of large non-selective pores in the lipid membrane (see ESI for details). 
Finally, pH gradient discharge mediated by these compounds was evaluated using the pH-sensitive dye pyranine (HPTS). Ionophoric activity correlates with the ability of anion transporters to facilitate the equilibration of the internal $\mathrm{pH}$ of vesicles upon imposing a $\mathrm{pH}$ gradient with the external solution. First of all, a calibration curve matching $\mathrm{I}_{460} / \mathrm{I}_{403}$ (corresponding to the excitation wavelengths of the probe's deprotonated and protonated forms, respectively) of an HPTS aqueous solution and the $\mathrm{pH}$ was built (see ESI for details). In this way, the emission values obtained from the HPTS assay can be converted into $\mathrm{pH}$ values. In order to perform the experiments, chloride- and HPTS-containing liposomes composed of a 7:3 POPC:cholesterol mixture are suspended in an isotonic sodium nitrate solution (see ESI for details). At $\mathrm{t}=30 \mathrm{~s}$ an aliquot of a sodium hydroxide aqueous solution is added, inducing an increase of the external $\mathrm{pH}$ close to one $\mathrm{pH}$ unit. Then, at $\mathrm{t}=60 \mathrm{~s}$, an aliquot of the corresponding carrier in DMSO is added and the changes in the fluorescence monitored over five minutes. The graphical representations are shown in Figure 4. The results showed a similar trend to that observed in the ion-selective-based transport assays. The essentially inactive transporters $\mathbf{L} \mathbf{1}$ and $\mathbf{L} \mathbf{2}$ induced almost no response in this assay, whereas the moderately active $\mathbf{L 3}$ induced a comparatively smaller change than the active L4-L8 (1\% mol carrier to lipid concentration). At this concentration, the response in the assay is quite similar for these compounds, although the activity of the compounds is concentration-dependent, as shown in Figure S55. 

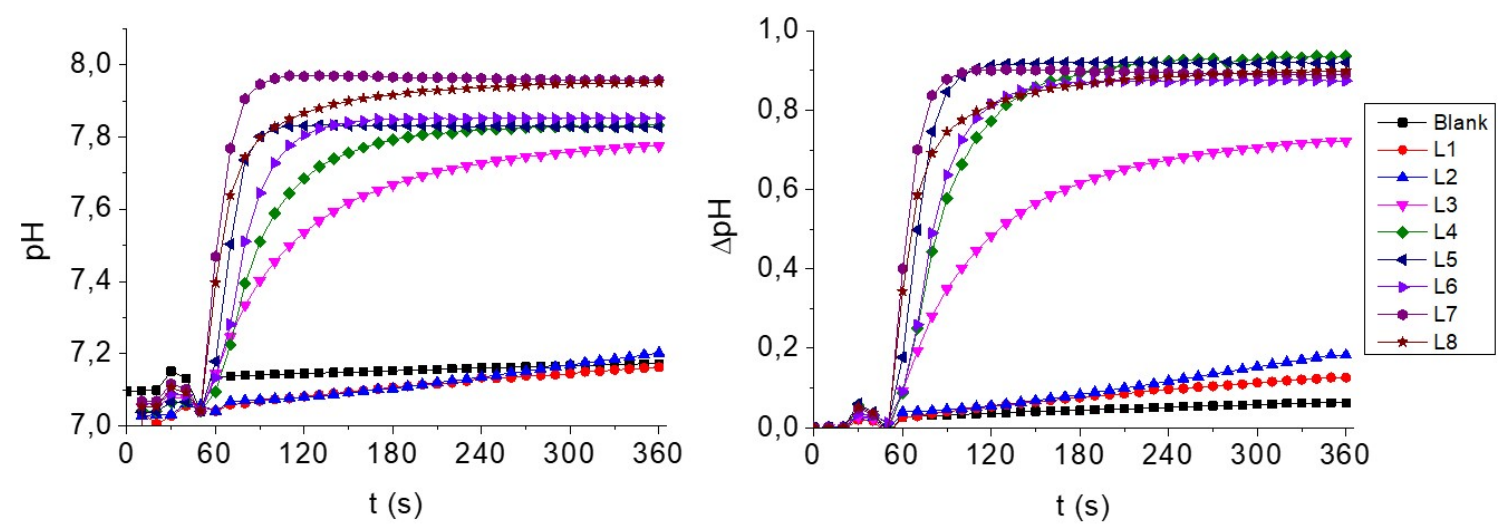

Figure 4. Variation of $\mathrm{pH}$ upon addition of the studied compounds to 7:3 POPC:cholesterol vesicles (0.5 mM POPC). Vesicles (loaded with $126.2 \mathrm{mM} \mathrm{NaCl}$ buffered at pH 7.2 with $10 \mathrm{mM}$ phosphate, and containing $10 \mu \mathrm{M}$ HPTS; I.S. $150 \mathrm{mM}$ ) were suspended in a $\mathrm{NaNO}_{3}$ solution $\left(126.2 \mathrm{mM} \mathrm{NaNO}_{3}\right.$ buffered at $\mathrm{pH} 7.2$ with 10 mM phosphate; I.S. $150 \mathrm{mM})$. At $\mathrm{t}=30 \mathrm{~s}$ an aliquot of a $\mathrm{NaOH}$ solution $(11 \mu \mathrm{L}, 0.5 \mathrm{M})$ was added, and at $\mathrm{t}=60 \mathrm{~s}$ the anion carrier ( $1 \%$ mol carrier to lipid concentration) was added. Each trace represents the average of at least three different trials, performed with at least three different batches of vesicles. Left: $\mathrm{pH}$ data obtained from the S-logistic model vs. time. Right: normalized $\mathrm{pH}$ data obtained from the S-logistic model vs. time.

\section{Conclusions}

In this work, we have explored eight isophthalamides/dipicolineamides, classic motifs in anion recognition, as transmembrane anion carriers. These compounds are easy-tomake and by selecting the appropriate aromatic substitution pattern, compounds displaying significant transmembrane transport activity can be prepared. Using potentiometric assays, chloride transport in the presence of nitrate and the biologically relevant bicarbonate facilitated by these derivatives was detected and quantified. Decoration of the aromatic substituents with trifluoromethyl- or pentafluorosulfanylgroups as in receptors L4-L6 resulted in the most active carriers of the series. The observed transport activity trend was found in good agreement with the $\mathrm{pH}$-driven 
HPTS experiment. We conclude that isophthalamides/dipicolineamides represent convenient motifs to develop active anion transporters whose activity can be tuned by choosing the appropriate aromatic substituents.

\section{Funding}

Funding from Consejería de Educación de la Junta de Castilla y León (project BU075G19) is gratefully acknowledged. Financial support from MIUR (PRIN 2017 project 2017EKCS35) is gratefully acknowledged by G.P. and C.C.

\section{Note}

Three dimensional X-ray data for L3 were collected on a BRUKER SMART APEX CCD diffractometer. Complex scattering factors were taken from the program SHELXL-2016 ${ }^{29}$ running under the WinGX program system ${ }^{30}$ as implemented on a

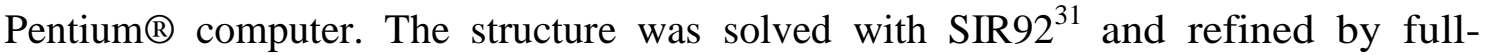
matrix least-squares on $\mathrm{F}^{2}$. All hydrogen atoms, except those corresponding to the $\mathrm{N}-\mathrm{H}$ fragments of the amide groups, which were refined freely in the final stages of refinement, were included in calculated positions and refined in riding mode. Refinement converged with anisotropic displacement parameters for all nonhydrogen atoms.

Crystal data for receptor L3: $\mathrm{C}_{20} \mathrm{H}_{14} \mathrm{Cl}_{2} \mathrm{~N}_{2} \mathrm{O}_{2}$; molecular weight $=385.23 \mathrm{~g} \cdot \mathrm{mol}^{-1}$; crystal system: monoclinic; space group: $P 2_{1} / c ; \mathrm{T}=298(2) \mathrm{K} ; a=$ 36.809(5) $\AA ; b=5.0601(7) \AA \AA ;=9.7506(13) \AA ; \alpha=90^{\circ} ; \beta=95.567(2)^{\mathrm{o}} ; \gamma$ $=90^{\circ} ; \mathrm{V}=1807.5(4) \AA^{3} ; \mathrm{F}(000)=792 ; \mathrm{Z}=4 ; \lambda\left(\mathrm{MoK}_{\alpha}\right)=0.71073 \AA$; $D_{\text {calc }}=1.416 \mathrm{~g} \cdot \mathrm{cm}^{-3} ; \mu=0.376 \mathrm{~mm}^{-1} . \mathrm{GOF}=0.945 .19218$ reflections measured $(2.22 \leq \Theta \leq 27.99)$, of which 4093 were unique ( $R_{\text {int }}$ : 0.1635), used in all calculations. The final $R_{1}$ was $0.0540(\mathrm{I}>2 \sigma(\mathrm{I}))$ and $w R_{2}$ was 0.1375 (all data). CCDC 1961241.

\section{References}


1 Gale, P. A.; Davis, J. T.; Quesada, R. Anion Transport and Supramolecular Medicinal Chemistry. Chem. Soc. Rev. 2017, 46, 2497-2519.

2 Gale, P. A.; Pérez-Tomás, R.; Quesada, R. Anion Transporters and Biological Systems. Acc. Chem. Res. 2013, 46 (12), 2801-2813.

3 Busschaert, N.; Gale, P. A. Small-Molecule Lipid-Bilayer Anion Transporters for Biological Applications. Angew. Chem. Int. Ed. 2013, 52 (5), 1374-1382.

4 Ashcroft, F. M. Ion Channels and Disease, Academic Press, San Diego, 2000.

5 Tosolini, M.; Pengo, P.; Tecilla, P. Biological Activity of Trans-Membrane Anion Carriers. Curr. Med. Chem. 2018, 25 (30) 3560-3576.

6 Busschaert, N.; Park, S.-H.; Baek, K.-H.; Choi, Y. P.; Park, J.; Howe, E. N. W.; Hiscock, J. R.; Karagiannidis, L. E.; Marques, I.; Félix, V.; Namkung, W.; Sessler, J. L.; Gale, P. A.; Shin, I. A Synthetic Ion Transporter that Disrupts Autophagy and Induces Apoptosis by Perturbing Cellular Chloride Concentrations. Nat. Chem. 2017, 9, 667-675.

7 Tapia, L.; Pérez, Y.; Bolte, M.; Casas, J.; Solà, J.; Quesada, R.; Alfonso, I. pH-Dependent Chloride Transport by Pseudopeptidic Cages for the Selective Killing of Cancer Cells in Acidic Microenvironments. Angew. Chem. Int. Ed. 2019, 58 (36), 12465-12468.

8 Kempf, J.; Schmitzer, A. R. Chem.-Eur. J. 2017, 23 (26), 6441-6451.

9 Carreira-Barral, I.; Rumbo, C.; Mielczarek, M.; Alonso-Carrillo, D.; Herran, E.; Pastor, M.; Del Pozo, A.; García-Valverde, M.; Quesada, R. Small Molecule Anion Transporters Display In Vitro Antimicrobial Activity Against Clinically Relevant Bacterial Strains. Chem. Commun. 2019, 55, 10080-10083.

$10 \mathrm{Wu}, \mathrm{X} . ;$ Gale, P. A. Small-Molecule Uncoupling Protein Mimics: Synthetic Anion Receptors as Fatty Acid-Activated Proton Transporters. J. Am. Chem. Soc. 2016, 138 (50), 16508-16514.

11 Hernando, E.; Capurro, V.; Cossu, C.; Fiore, M.; García-Valverde, M.; Soto-Cerrato, V.; Pérez-Tomás, R.; Moran, O.; Zegarra-Moran, O.; Quesada, R. Small Molecule Anionophores Promote Transmembrane Anion Permeation Matching CFTR Activity. Sci. Rep. 2018, 8, 2608. 
12 Gale, P. A.; Howe, E. N. W.; Wu, X. Anion Receptor Chemistry. Chem. 2016, 1 (3), 351422.

13 Clarke, H. J.; Van Rossom, W.; Horton, P. N.; Light, M. E.; Gale, P. A. Anion Transport and Binding Properties of $N, N^{\prime}$-(Phenylmethylene)Dibenzamide Based Receptors. Supramol. Chem. 2016, 28 (1-2), 10-17.

14 Kavallieratos, K.; Bertao, C. M.; Crabtree, R. H. Hydrogen Bonding in Anion Recognition: A Family of Versatile, Nonpreorganized Neutral and Acyclic Receptors. J. Org. Chem. 1999, 64, 1675-1683.

15 Berry, S. N.; Busschaert, N.; Frankling, C. L.; Salter, D.; Gale, P. A. Aromatic Isophthalamides Aggregate in Lipid Bilayers: Evidence for a Cooperative Transport Mechanism. Org. Biomol. Chem. 2015, 13, 3136-3143.

16 Yamnitz, C. R.; Negin, S.; Carasel, I. A.; Winter, R. K.; Gokel, G. W. Dianilides of Dipicolinic Acid Function as Synthetic Chloride Channels. Chem. Commun. 2010, 46, 2838-2840.

17 Gale, P. A.; Garric, J.; Light, M. E.; McNally, B. A.; Smith, B. D. Conformational Control of $\mathrm{HCl}$ Co-Transporter: Imidazole Functionalised Isophthalamide vs. 2,6Dicarboxamidopyridine. Chem. Commun. 2007, 1736-1738.

18 Santacroce, P. V.; Davis, J. T.; Light, M. E.; Gale, P. A.; Iglesias-Sánchez, J. C.; Prados, P.; Quesada, R. Conformational Control of Transmembrane $\mathrm{Cl}^{-}$Transport. J. Am. Chem. Soc. 2007, 129, 1886-1887.

19 Liu, P.-Y.; Li, S.-T.; Shen, F.-F.; Ko, W.-H.; Yao, X.-Q.; Yang, D. A Small Synthetic Molecule Functions as a Chloride-Bicarbonate Dual-Transporter and Induces Chloride Secretion in Cells. Chem. Commun. 2016, 52, 7380-7383.

20 Spooner, M. J.; Li, H.; Marques, I.; Costa, P. M. R.; Wu, X.; Howe, E. N. W.; Busschaert, N.; Moore, S. J.; Light, M. E.; Sheppard, D. N.; Félix, V.; Gale, P. A. Fluorinated Synthetic Anion Carriers: Experimental and Computational Insights Into Transmembrane Chloride Transport. Chem. Sci. 2019, 10, 1976-1985. 
21 Knight, N. J.; Hernando, E.; Haynes, C. J. E.; Busschaert, N.; Clarke, H. J.; Takimoto, K.; García-Valverde, V.; Frey, J. G.; Quesada, R.; Gale, P. A. QSAR Analysis of Substituent Effects on Tambjamine Anion Transporters. Chem. Sci. 2016, 7, 1600-1608.

$22 \mathrm{Li}, \mathrm{Z}$; Chen, W.-H. Application of Lipophilic Balance Modification in the Creation of Potent Synthetic Anionophores. Mini-Rev. Med. Chem. 2017, 17 (14), 1398-1405.

23 Hynes, M. J. EQNMR: A Computer Program for the Calculation of Stability Constants From Nuclear Magnetic Resonance Chemical Shift Data. J. Chem. Soc. Dalton Trans. 1993, 311-312.

24 Jowett, L. A.; Gale, P. A. Supramolecular Methods: the Chloride/Nitrate Transmembrane Exchange Assay. Supramol. Chem. 2019, 31, 297-312.

25 Marcus, Y. Thermodynamics of Solvation of Ions. J. Chem. Soc. Faraday Trans. 1991, 87 (18), 2995-2999.

26 Vargas Jentzsch, A.; Hennig, A.; Mareda, J.; Matile, S. Synthetic Ion Transporters that Work with Anion- $\pi$ Interactions, Halogen Bonds, and Anion-Macrodipole Interactions. Acc. Chem. Res. 2013, 46 (12), 2791-2800.

27 Giese, M.; Albrecht, M.; Rissanen, K. Anion- $\pi$ Interactions with Fluoroarenes. Chem. Rev. 2015, 115 (16), 8867-8895.

28 AlogPs calculated with VCCLAB, Virtual Computational Chemistry Laboratory: http://www.vcclab.org (last access: September 2019). Tetko, I. V.; Gasteiger, J.; Todeschini, R.; Mauri, A.; Livingstone, D.; Ertl, P.; Palyulin, V. A.; Radchenko, E. V.; Zefirov, N. S.; Makarenko, A. S.; Tanchuk, V. Y.; Prokopenko, V. V. Virtual Computational Chemistry Laboratory - Design and Description. J. Comput. Aid. Mol. Des. 2005, 19 (6), 453-463.

29 SHELXL-2016: Sheldrick, G. M. A Short History of SHELX. Acta Cryst. 2008, A64, 112122.

30 WinGX: Farrugia, L. J. WinGX Suite for Small-Molecule Single-Crystal Crystallography. J. Appl. Cryst. 1999, 32, 837-838. 
31 SIR92: Altomare, A.; Cascarano, G.; Giacovazzo, C.; Guagliardi, A.; Burla, M. C.; Polidori, G.; Camalli, M. SIR-92 - A Program for Automatic Solution of Crystal Structures by Direct Methods. J. Appl. Cryst. 1994, 27, 435. 